\title{
A kinesthesiometer for assessing digital passive movement sensitivity in man
}

\author{
HOWARD L. COHEN, WILLIAM S. BATTERSBY, KARL REGNAT, \\ and LAWRENCE FELDMAN \\ Queens College, Flushing, New York 11367
}

\begin{abstract}
An electromechanical system for the delivery of kinesthetic stimulation to human digits is described. The system provides highly precise control over angular velocity (in degrees per second), angular displacement (in degrees), and stimulus duration (in seconds) and uses an electromagnetic brake to terminate the stimuli. It also permits three measures of passive movement sensitivity to be made: correct detections, response time, and angular displacement.
\end{abstract}

Most psychophysical studies of passive movement sensitivity in man (for reviews, see Goodwin, 1976; Goodwin, McCloskey, \& Matthews, 1972; McCloskey, 1978) have produced highly variable and even contradictory results, in part due to poor stimulus control and in part due to imprecision in measuring the dependent variable (angular displacement of a movable joint). A variety of drive systems have been used to produce angular rotation of a joint. Systems as diverse as hydraulic (Goldscheider, 1889; Horch, Clark, \& Burgess, 1975), electromechanical (Browne, Lee, \& Ring, 1954; Gandevia \& McCloskey, 1976; Kokmen, Bossemeyer, \& Williams, 1977), and even manual (Laidlaw \& Hamilton, 1937) have all been used. Similarly, there have been wide differences in the techniques used to measure the angular displacement threshold, including reading the values from a scale (Browne et al., 1954; Goldscheider, 1889; Laidlaw \& Hamilton, 1937), from an ink-writer deflection (proportional to the angular displacement) (Gandevia \& McCloskey, 1976; Horch et al., 1975), and even from a minicomputer digital display (Kokmen et al., 1977). Of equal importance with the differences in measurement technique is the fact that none of the systems used so far has included a brake mechanism to terminate rotation when the response is made. Because of both inertia in the system and the elapsed reaction time between detection and measurement, it is likely that the angular displacement measured is larger than that needed for detection.

The present electromechanical system was designed to provide more precise stimulus control and more accurate response measurement, as well. It delivers kinesthetic stimuli over a range of more than two log units of angular velocity (in degrees per second) and in two directions (up and down). It can also produce "blanks" or "catch" trials, during which no movement occurs. The system allows three measures of passive movement sensitivity to be made: correct detections, response time, and angular displacement at threshold. Response time consists of two temporal components: the stimulus duration required for move- ment detection plus the reaction time of the observer. Angular displacement (in degrees) is obtained by multiplying the preset stimulus velocity (in degrees per second) by the response time (in seconds).

\section{GENERAL DESCRIPTION OF THE SYSTEM}

Figure 1 is a block diagram of the stimulus delivery/ response measurement system, and Figure 2 is a diagram of the kinesthetic stimulator. The system's major components include a 12-speed reversible motor whose output operates through a series of connecting rods to produce movement of a finger around an axis, a series of pulse and waveform generators for time control, an electromagnetic clutch brake for stimulus termination, a subject response key to indicate movement detection, and an electric timer to measure response time to $\pm .01 \mathrm{sec}$. Three additional components are a four-channel polygraph, a regulated power supply, and

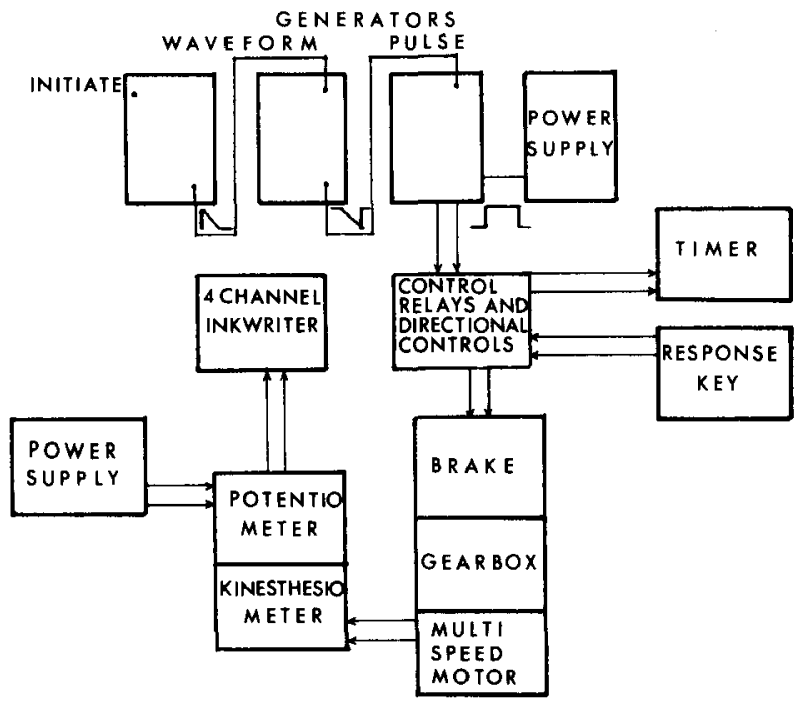

Figure 1. Block diagram of the complete system for stimulus delivery, response measurement, and calibration. 


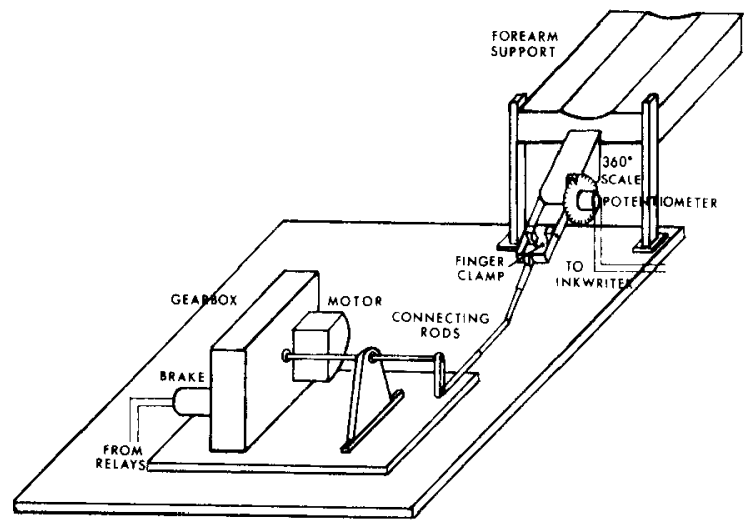

Figure 2. Diagram of the stimulus delivery system for kinesthetic stimulation.

continuous-turn potentiometer, which are used to calibrate the system.

\section{SYSTEM OPERATION}

The heart of the stimulus delivery system is a multiple-speed motor (Holtzer-Cabot CS-147, 600-rpm, reversible, synchronous motor) driving an input shaft through a Harvard Apparatus No.600 multispeed transmission. On the latter, a selector gear is used to engage any one of 12 possible speeds of the output shaft and, in the neutral position, to disengage it. The output shaft is attached via an adjustable cam to a series of variable-length connecting rods that connect, in turn, to an arm that rotates and produces the kinesthetic stimulus. The output angular velocity of the moving arm is approximately doubled through each gearshift, and the velocity may be varied by changing the length of the connecting rods or the cam. (One series of experiments used stimulus velocities of $.05, .10, .15, .30, .80,1.5$, 6.2 , and $11.0 \mathrm{deg} / \mathrm{sec}$.)

The moving arm is fitted with a padded, spring-loaded finger clamp that, by exerting lateral pressure, helps to minimize directional cues that may come from securing the digit from above and below and is the method used in the clinical assessment of passive movement sensitivity. On several occasions during the experiments that were conducted, subjects reported that pressure from the clamp produced throbbing sensations that interfered with movement detection. The problem was alleviated by substituting springs of lesser tension that had no observable effect on threshold sensitivity.

Attached to one end of the moving arm is a pointer indicating angular displacement on a 360-deg scale. This scale, calibrated in 1-deg intervals, is mounted at the axis of rotation. Fitted through this axis is the shaft of a potentiometer (TIC Model S262 continuous turn, servomount, $3.5 \mathrm{kohms}, .5 \%$ linearity). In order to calibrate the system, a voltage from a regulated power supply (Hewlett-Packard 6216A) is placed across the potentiometer, and the output is fed into an ink writer
(Grass Type 5D four-channel polygraph), producing a voltage displacement proportional to the angular displacement of the arm.

The overall timing control for the kinesthetic stimulus is provided by a waveform generator (Tektronix Type 162) that triggers a second identical unit, which, in turn, provides a negative sawtooth time base for a pulse generator (Tektronix Type 161). This pulse generator energizes a series of relays, thereby initiating three events simultaneously. First, it deenergizes an electromagnetic brake (Simplatrol Model CB-50 clutch brake) externally mounted around the extended motor gear shaft, thus permitting rotation of the output shaft to occur. At the same time, it activates the moving arm at a preset velocity, in a given direction (up or down), for a preset time ( $10 \mathrm{sec}$ maximum). Finally, it activates a timer (Standard Electric) that reads to $\pm .01 \mathrm{sec}$. The experimenter initiates a trial by manually operating the first waveform generator. The subject is required to respond to the detection of movement by pressing a telegraph key. This energizes the brake, terminates the stimulus, and stops the timer so that response time can be recorded. If the subject does not detect movement within $10 \mathrm{sec}$, the offset of the timing pulse initiates the same sequence.

The subject is seated beside and slightly behind the stimulus delivery system. The right forearm is placed perpendicular to the upper arm and is supported by a horizontal wooden armrest with a shallow trough running down the middle. The hand is ventroflexed at an angle of about $45 \mathrm{deg}$, and the palm and fingers are placed upon another wooden rest and are secured with an elastic bandage. The right index finger is extended and strapped down between the metacarpophalangeal and the proximal interphalangeal joints. The clamp is then applied to the lateral surfaces of the finger, between the proximal and distal interphalangeal joints, so that the forces securing the joint are applied perpendicular to the plane of movement.

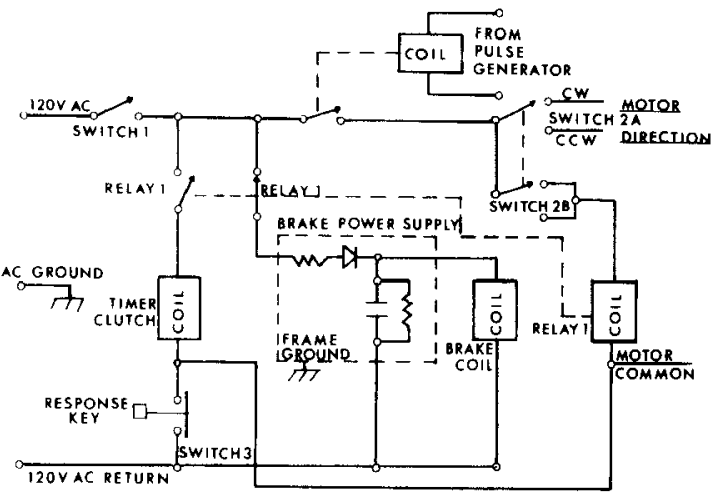

Figure 3. The schematic diagram for stimulus timing, brake activation, directional control, and response measurement. 


\section{CONCLUSION}

The system provides a precise, reliable means of establishing passive movement thresholds in man. Not only does it allow threshold determination in normal subjects, but also it enables the clinician to detect the small changes occurring during the progression of, or recovery from, neurologic disorders. Its precision and reliability are attested to by the stability of the calibrated output angular velocities and by the uniformity of the experimental data generated. In over 2 years of regular use, the sole component needing replacement was a diode in the clutch brake power supply. The mechanical components, regularly lubricated with a commercial product (e.g., WD-40), never needed replacement.

\section{REFERENCES}

Browne, K., Lee, J., \& Ring, P. A. The sensation of passive movment at the metatarsophalangeal joint of the great toe of man. Jourmal of Physiology (London), 1954, 126, 448-458.

Gandevia, S. C., \& McCloskey, D. I. Joint sense, muscle sense, and their combination as position sense, measured at the distal interphalangeal joint of the middle finger. Journal of Physiology (London), 1976, 260, 387-407.

Goldscheider, A. Untersuchungen uber den Muskelsinn. Arch. Archiv fur Anatomie und Physiologie (Leipzig), 1889, 3, 369-502.

Goodwin, G. M. The sense of limb position and movement. In J. Keough \& R. S. Hutton (Eds.), Exercise and Sport Sciences Reviews, 1976, 4, 87-124.

Goodwin, G. M., McCloskey, D. I., Matthews, P. B. C. The contribution of muscle afferents to kinesthesia shown by vibration induced illusions of movement and by the effect of paralyzing joint afferents. Brain, 1972, 95, 705-748.

Horch, K. W., Clark, F. J., \& Buraess, P. R. Awareness of knee joint angle under static conditions. Journal of Neurophysiology, 1975, 38, 1436-1447.

Kormen, E., Bossemeyer, R. W., \& Williams, W. J. Quantitation of motion perception in the digits: A psychophysical study in normal human subjects. Annals of Neurology, 1977 , 2, 279-284.

Laidlaw, R. W., \& Hamilton, M. A. The quantitative measurement of apperception of passive movement. Bulletin of the Neurological Institute of New York, 1937, 6, 145-153.

McCloskey, D. I. Kinesthetic sensibility. Physiological Reviews, $1978,58,763-820$.

(Received for publication February 26, 1981; accepted April 9, 1981.) 